\title{
Crunch: Analysis of the phenomenon in the independent game development scene
}

\author{
Keywords \\ Crunch, Crunch time, Independent Games, Video games industry.
}

This paper presents arguments to explain the complexity of developing and producing a digital game (SCHREIER, 2018), which can culminate in unhealthy labor practices known as "crunch time" or simply "crunch". During crunch time, employees often work up to 90 hours a week, often as the release date approaches or there is a marketing event ahead - E.g., the Electronic Entertainment Expo. However, it is not uncommon for studios to run for years on a crunch schedule. A recent well-known example was Cyberpunk 2077 (CD Projekt Red, 2020), which had employees coming out to report abusive years' worth of abusive management. Another prominent example is Sony's Naughty Dog, LLC, famous for its excessive work culture. The phenomenon is not recent either, it received public attention for the first time in 2004 when the spouse of an EA employee reported the damage caused in her household by the work culture in the company (HOFFMAN, 2006). We identified a direct connection between incidences of "crunch" to specific sociocultural factors present in the games industry and the dependency relations - creative, financial, and publishing (GARDA \& GRABARCZYK, 2016). We state that the business and labor culture in the videogames industry culminates in negative effects on the personal lives and mental health of its employees. Woodcock (2020) also links the crunch culture to a sexist employability condition, claiming that the industry avoids hiring women who are more likely to have household obligations and thus are unable to cope with crunch. We seek to understand if there is a correlation between a high incidence of crunch, pressure from the financing agencies, and inflexible deadlines. We speculate, based on the work of Schreier (2018) and analyzing the stories behind the development of the acclaimed "Stardew Valley" (BARONE, 2016) that even without external pressure, crunch might still happen. Han's work (2017) states the "achievement-subject" as one who does not distinguish work from its personal life, we position the independent videogame developer as one who is always competing against themselves, exploiting themselves to exhaustion. This is made worse, since, according to Edholm and Lindström (2016), crunch time is already considered as a "necessary evil" by the industry workers and is taught to aspiring game developers in universities (ANTHROPY, 2012). In 2019, the International Game Developers Association released that $42 \%$ of the game industries' employees were submitted to crunch and only $8 \%$ of these were compensated for the overtime. Cote and Harris (2020) also state that most of the game industries' professionals are expected to leave their jobs between 3 and 9 years of labor. Through reviewing the literature and analyzing post-mortem documents, this paper lays out aspects that influence this behavior and show examples of how it can affect a worker's life and mental health. This paper attributes the high incidence of burnout syndrome among videogames industry workers and the high number of employees leaving the videogames industry to crunch time. In the independent scene, we investigate how sociocultural factors can contribute to a (un)healthy relationship with labor. 